\title{
Testing Relationships between Energy and Vertebrate Abundance
}

\author{
Chris Carbone and Nathalie Pettorelli \\ Institute of Zoology, Zoological Society of London, Regent's Park, London NW1 4RY, UK \\ Correspondence should be addressed to Nathalie Pettorelli, nathalie.pettorelli@ioz.ac.uk
}

Received 4 June 2009; Accepted 3 August 2009

Recommended by Panos V. Petrakis

Understanding what drives variation in the abundance of organisms is fundamental to evolutionary ecology and wildlife management. Yet despite its importance, there is still great uncertainty about the main factors influencing variation in vertebrate abundance across taxa. We believe valuable knowledge and increased predictive power could be gained by taking into account both the intrinsic factors of species and the extrinsic factors related to environmental surroundings in the commonly cited $R Q$ model, which provides a simple conceptual framework valid at both the interspecific and the intraspecific scales. Approaches comparing studies undertaken at different spatial and taxonomic scales could be key to our ability to better predict abundance, and thanks to the increased availability of population size data, global geographic datasets, and improved comparative methods, there might be unprecedented opportunities to (1) gain a greater understanding of vertebrate abundance patterns and (2) test existing theories on free-ranging animals.

Copyright (c) 2009 C. Carbone and N. Pettorelli. This is an open access article distributed under the Creative Commons Attribution License, which permits unrestricted use, distribution, and reproduction in any medium, provided the original work is properly cited.

\section{Introduction}

Understanding the factors driving patterns in abundance of living organisms is a central challenge in ecology $[1,2]$, being of both theoretical and practical importance in wildlife management and conservation biology [3]. Such challenge has been defined at different spatiotemporal scales, ranging from understanding temporal variation in abundance at a population scale, a major aim of population dynamics studies [4], to understanding spatial variation in abundance at global scales, one of the major aims of macroecology $[1,2]$.

At global scales, resource use and supply are often assumed to be major factors driving variation in vertebrate abundance [5-11] and species richness (More Individuals Hypothesis (MIH) [12, 13]). Yet because factors linked with energy are not specifically measured, these assumptions remain highly controversial [13-19]. In addition, studies have been criticized for failing to consider confounding factors [20] and the ecological context in which estimates have been made [21] and overall this situation has led to a lack of generality and precision in previous work as well as poor statistical fits to expected patterns. Here we provide a short perspective on how one might gain a greater understanding of abundance patterns in vertebrates, at a range of spatial scales through the use of improved analyses taking into account intrinsic factors (e.g., biological traits) and extrinsic factors (e.g., environmental factors) determining energy use and availability (Table 1).

\section{Resource Availability and Vertebrate Abundance: A Simple Framework}

In order to illustrate our perspective on the importance of defining factors related to energy use and supply, we use a commonly cited simple ecological model $[5,22-$ 24]. The model assumes abundance varies as a function of resource supply and resource use, that is, $N \propto R / Q$ where $N$ is consumer abundance, $Q$ the consumer resource requirements, and $R$ the resource supply rate.

Damuth [5] originally defined $Q$ as the consumer resource requirements, which is linked to metabolic rate $[5,6,25]$. By far the most common measure to approximate $Q$ is Basal Metabolic Rate (BMR [26-28]). Yet basal metabolic rate is measured in captivity under fasting and resting conditions and often represents only a fraction of normal resource requirements in the wild, which are better represented by Field Metabolic Rate (FMR [29]). In addition, 
TABLE 1: Possible factors affecting the strength of the energy/abundance relationship at both the intraspecific and interspecific levels. $Q$ refers to the consumer resource requirements, $R$ refers to the resource supply rate, $I$ refers to intrinsic factors (e.g., biological traits), while $E$ stands for extrinsic factors (e.g., environmental factors).

\begin{tabular}{lcll}
\hline Variable & Intrinsic/Extrinsic & Possible factors (intraspecific level) & Possible factors (interspecific level) \\
\hline & $I$ & $\begin{array}{l}\text { Age/Size structure of the populations considered } \\
\text { Average climatic conditions }\end{array}$ & $\begin{array}{l}\text { Body temperature, Phylogeny } \\
\text { Average climatic conditions }\end{array}$ \\
\hline$R$ & $E$ & Competition intensity, predation level & $\begin{array}{l}\text { Diet (when considering indirect measures of } \\
\text { resource abundance such as satellite-based } \\
\text { indices of primary productivity) }\end{array}$ \\
& $I$ & $\begin{array}{l}\text { Spatial location of the studied population within } \\
\text { the distribution range of the species }\end{array}$ & $\begin{array}{l}\text { Competitive skills, trophic position, social } \\
\text { system }\end{array}$ \\
\hline
\end{tabular}

BMR can scale differently from FMR with respect to mass for different taxonomic groups and this can profoundly influence our estimates of metabolic rate for species varying widely in size [30]. Unfortunately, measuring FMR is difficult and costly and there are only a limited number of species for which FMR has been obtained [29]. FMR estimates are especially rare for larger species $(20 \mathrm{~kg}+)$ and this forces us to speculate on field requirements for these species, either through the use of surrogate measures (e.g., BMR [31]), intake rates or activity budgets [32], or theoretical arguments [33].

Typically, approximations of $Q$ are thus based on body mass, since this parameter has been shown to be closely linked to basal metabolic rate [34]. Across taxonomically similar species, $Q$ can be represented as a simple function of body mass $(M)$ as the power equation $Q \propto M^{q}$, where $q$ is the resource requirement scaling exponent. Earlier work $[5,25]$ also found evidence that the density scaling in animals from a range of taxonomic groups falls near the inverse of the expected metabolic rate scaling, $N \propto M^{-q}$. Damuth concluded then, as an approximation, that total population energy use $N Q(=R)$ does not vary systematically across species, or NQ $\propto M^{0}$. This empirical result, described as "energy equivalence" $[22,35]$, implies that resource supply rate $R$ is independent of body mass, $R \propto M^{0}$. This view is, for example, supported in terrestrial mammals where good fit between animal abundance and animal body mass has been reported [5, 23, 25] (Figure 1(a)).

Energy equivalence is however difficult to justify on theoretical grounds especially at global scales $[15,18]$ and has not been well supported within other taxonomic groups (e.g., birds (see Figure 1(b)) $[15,16]$ or on smaller spatial scales $[15,18]$. Despite these conflicting views, there is a lot of evidence that food resources are limiting in many systems, especially in intraspecific studies where positive relationships between food abundance and population density are commonly reported (e.g., [37-43]).

\section{Moving Forward}

Having established the view that energy supply and energy use are critical factors driving patterns in animal abundance, we believe a framework defining how abundance studies vary across taxonomic and spatial scales can help us to develop and focus future research. We present a range of potential complementary approaches, based on the belief that working at different spatial and taxonomic scales is needed to get a complete and integrated understanding of the factors influencing abundance patterns.

3.1. Quantifying Factors Related to Resource Supply, R. Intraspecific studies of abundance patterns on vertebrates have been most successful at incorporating resource information and the same success could be expected by making use of the recent availability of global, detailed spatial datasets regarding primary productivity and climate as well as the large range of intraspecific studies which quantify prey availability (e.g., [37-44]) in interspecific comparisons in abundance. Resource supply rate could indeed be indexed using (i) indirect measures such as rainfall [37] or energy availability derived from satellite data $[45,46]$ or (ii) direct measures such as prey abundance, biomass, or productivity of resources per unit area [47].

Even though the consideration of such information represents an important step forward, one should keep in mind that indirect measures might not be linearly correlated to resource supply, and the strength of the correlation with resource supply might be dependent on the location and the species considered. For example, herbivore food plants vary greatly in their digestibility so that a satellite-based index (such as the Normalized Difference Vegetation Index (NDVI) [46]) or food volume may not have much meaning to species which select less dominant plant species [48-51]. In addition to resource availability, other factors may have an important influence on abundance, such as the importance of intraspecific and interspecific competition and predation, as these may affect the proportion of available resources that can be allocated to the species considered [52-57]. Across ecologically similar species, there is, for example, sometimes considerable dietary overlap between species $[58,59]$, so that studies of abundance may be improved by considering local richness of competing species [18, 21]. Another factor potentially affecting resource supply is the spatial location of the population under study within the species range [60]. Densities have often been assumed to be lower at the edge of a geographic range [61,62], although there is limited empirical evidence for such systematic patterns [63]. Finally, 


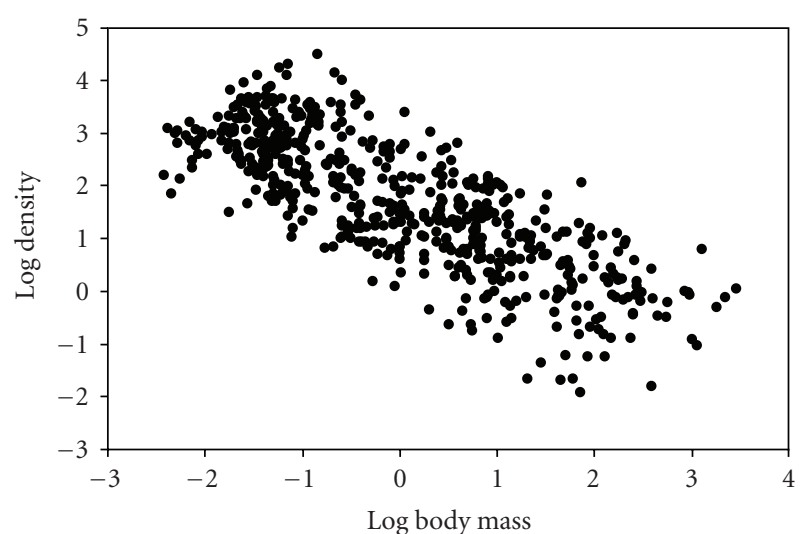

(a)

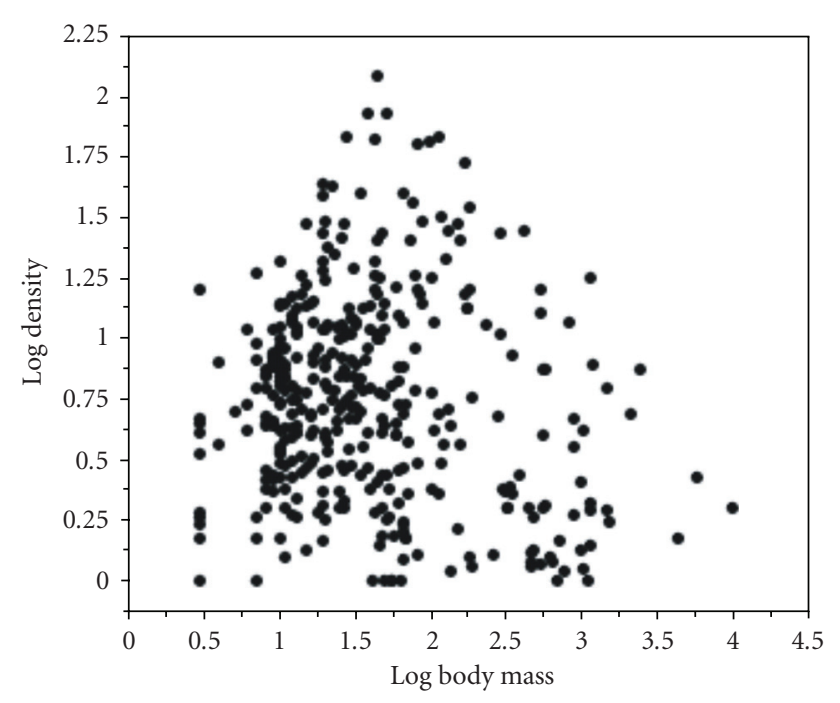

(b)

Figure 1: Relationship between the $\log _{10}$ of body mass and $\log _{10}$ of density for (a) all mammals (figure based on the original data from Damuth [25]) and (b) birds in North America (figure extracted from Gaston and Blackburn [2]). For mammals, body mass is expressed in $\mathrm{kg}$ while density is measured as the number of individuals per $\mathrm{km}^{2}$. For birds, body mass is expressed in $\mathrm{g}$ while density is measured as the number of individuals per Breeding Bird Survey (BBS) route (see Brown and Maurer [36] for the original dataset description). As it can be seen, body mass is tightly linked to density for mammals (slope $=-0.78, r=-0.80, N=467$; from Damuth [25]), while the linear relationship between body mass and density is far less tight for birds (slope $=-0.08, r=-0.13$, $N=368$; these estimates are based on data reconstruction and subsequent analysis from the original data presented in Brown and Maurer [36, Figure 2]).

when considering scaling relationships, the productivity of resources (measured as biomass/time), rather than biomass alone, provides a more appropriate measure of resource supply $[21,23,64]$.

3.2. Quantifying Factors Related to Resource Use, Q. Studies which have focused on traits associated with variation in resource use, $Q$, have largely been based on interspecific studies at global $[5,6,65]$ and local $[7,11,66,67]$ scales. This is due to the ease with which one can associate differences in size with metabolic rate and resource use [6]. There is, however, the potential to use natural variation in body size within species, to test for the effects of variation in resource requirements. In some species, adult body mass varies several fold across populations (e.g., marine iguana Amblyrhynchus cristatus; [68]). Such species provide a great opportunity to explore how abundance varies with mass without added confounding species effects. Size during ontogeny can also vary greatly for some species (e.g., reticulated python Python reticulates; $[69,70])$ and there may be the potential in some of these species to examine variation in abundance with growth.

Species do not then represent independent entities, and several studies have suggested that phylogeny might influence the energy/abundance relationship [71]. Across taxonomic groups, species however vary greatly in the physiology and ecology. Endothermic mammals and birds have, for example, been previously reported to have field metabolic rate about 12 and 20 times higher, respectively, than field metabolic rates of equivalent-sized, ectothermic, species (e.g., reptiles; [30]). Likewise, island species of lizards were shown to display consistently higher apparent digestive efficiency than their mainland sibs [72]. Such results highlight the multiple ways in which phylogeny might affect energy-abundance relationships, depending on the phylogenetic scale considered (e.g., endothermic versus ectothermic species; carnivorous mammals versus herbivorous mammals; island versus mainland species). Average climatic conditions (e.g., temperature) experienced by individuals might then influence their metabolic rates, especially in ectothermic species [73]. A key factor that might finally influence the use of resources, space use, and abundance patterns might be the mode of transport $[6,34]$. Birds are indeed capable of travelling large distances between food patches compared to mammals and this allows the potential for small species to range widely and occur at low population densities [2]. This might explain the striking differences between birds and mammals in body mass-abundance relationships (Figure 1).

3.3. Building Up a Broad Conceptual Model of Density Variation Based on Detailed Case Studies. Testing separate components of the $R Q$ model using smaller subsets of data which are designed to control for other factors could constitute a complementary approach to developing an integrated understanding of the factors affecting $R, Q$, and ultimately $N$. The idea would be, for example, to consider several single species systems from different taxonomic groups to gather knowledge on the factors determining $R$ and $Q$ at this lower scale, in order ultimately to build a broad conceptual model of abundance variation. In indeterminate growing organisms, one could also look at a combination of factors related to $R$ and $Q$ where both body mass and resources may vary across sites and stages of development: this could, for example, be done in reptiles [69], where different age classes live independently and may have different abundance size scaling relationships. 
Such knowledge could be gathered using both experimentation and comparative observational studies on focal species. For example, species metabolism (sometimes used to index $Q$ ) is expected to vary with environmental conditions such as temperature, and this is especially for ectotherms. Experimentation could help quantifying this relationship for many species, while information on temperature conditions could be integrated in models exploring the relationships between consumer resource requirements, resource supply rate, and the abundance of the focal species.

\section{Conclusions}

Understanding the relationship between energy and abundance is a fundamental question in ecology, being posed at all spatial scales and for all organisms. When it comes to macroecology, the next challenge is to gain greater predictive understanding of abundance patterns, taking into account both the intrinsic factors of species and the extrinsic factors related to environmental surroundings. In that respect, the $R Q$ model provides a simple conceptual framework to understand abundance patterns in vertebrates, valid at both the interspecific and the intraspecific scales to face such challenge. This simple model allows identifying current gaps in our general understanding of the factors structuring abundance variation, highlighting the need to consider both resource supply and resource use. The challenge lies in correctly indexing $R$ and $Q$, and we believe gaining a deeper understanding of the factors influencing resource accessibility and energy requirements at different scales and for different species will help identify better proxies of these crucial parameters. Previous analogous conceptual approaches, such as the ideal free distribution model [52], have demonstrated their usefulness in developing an understanding of animal distributions [74], and the RQ model could be as successful in developing an understanding of spatiotemporal variation in animal abundance.

\section{Acknowledgments}

The authors thank Peter Bennett and Tim Blackburn for helpful comments on earlier drafts of the manuscript.

\section{References}

[1] J. H. Brown, Macroecology, Chicago University Press, Chicago, Ill, USA, 1995.

[2] K. J. Gaston and T. M. Blackburn, Patterns and Process in Macroecology, Blackwell Scientific, Oxford, UK, 2000.

[3] M. E. Soulé, Conservation Biology: The Science of Scarcity and Diversity, Sinauer Associates, Sunderland, Mass, USA, 1986.

[4] M. Begon, J. L. Harper, and C. R. Townsend, Ecology: Individuals, Populations and Communities, Blackwell Scientific, Oxford, UK, 1986.

[5] J. Damuth, "Population density and body size in mammals," Nature, vol. 290, no. 5808, pp. 699-700, 1981.

[6] R. H. Peters, The Ecological Implications of Body Size, Cambridge University Press, Cambridge, UK, 1983.
[7] P. A. Marquet, S. A. Navarrete, and J. C. Castilla, "Scaling population density to body size in rocky intertidal communities," Science, vol. 250, no. 4984, pp. 1125-1127, 1990.

[8] B. J. Enquist, J. H. Brown, and G. B. West, "Plant energetics and population density-reply," Nature, vol. 398, no. 6728, p. $573,1999$.

[9] B. J. Enquist and K. J. Niklas, "Invariant scaling relations across tree-dominated communities," Nature, vol. 410, no. 6829, pp. 655-660, 2001.

[10] A. Belgrano, A. P. Allen, B. J. Enquist, and J. F. Gillooly, "Allometric scaling of maximum population density: a common rule for marine phytoplankton and terrestrial plants," Ecology Letters, vol. 5, no. 5, pp. 611-613, 2002.

[11] J. L. Ackerman, D. R. Bellwood, and J. H. Brown, "The contribution of small individuals to density-body size relationships: examination of energetic equivalence in reef fishes," Oecologia, vol. 139, no. 4, pp. 568-571, 2004.

[12] D. S. Srivastava and J. H. Lawton, "Why more productive sites have more species: an experimental test of theory using treehole communities," American Naturalist, vol. 152, no. 4, pp. 510-529, 1998.

[13] A. H. Hurlbert, "Species-energy relationships and habitat complexity in bird communities," Ecology Letters, vol. 7, no. 8, pp. 714-720, 2004.

[14] T. M. Blackburn, V. K. Brown, B. M. Doube, J. J. D. Greenwood, J. H. Lawton, and N. E. Stork, "The relationship between abundance and body size in natural animal assemblages," Journal of Animal Ecology, vol. 62, no. 3, pp. 519-528, 1993.

[15] P. Cotgreave, "The relationship between body size and population abundance in animals," Trends in Ecology and Evolution, vol. 8, no. 7, pp. 244-248, 1993.

[16] T. M. Blackburn and K. J. Gaston, "The relationship between animal abundance and body size: a review of the mechanisms," Advances in Ecological Research, vol. 28, pp. 181-210, 1999.

[17] K. S. Smallwood, "The allometry of density within the space used by populations of mammalian Carnivora," Canadian Journal of Zoology, vol. 79, no. 9, pp. 1634-1640, 2001.

[18] E. P. White, S. K. M. Ernest, A. J. Kerkhoff, and B. J. Enquist, "Relationships between body size and abundance in ecology," Trends in Ecology \& Evolution, vol. 22, pp. 323-330, 2007.

[19] D. A. Yee and S. A. Juliano, "Abundance matters: a Weld experiment testing the more individuals hypothesis for richnessproductivity relationships," Oecologia, vol. 153, pp. 153-162, 2007.

[20] K. J. Gaston, T. M. Blackburn, J. J. D. Greenwood, R. D. Gregory, R. M. Quinn, and J. H. Lawton, "Abundanceoccupancy relationships," Journal of Applied Ecology, vol. 37, pp. 39-59, 2000.

[21] P. A. Marquet, "Of predators, prey, and power laws," Science, vol. 295, no. 5563, pp. 2229-2230, 2002.

[22] J. Damuth, "Ecology—of size and abundance," Nature, vol. 351, no. 6324, pp. 268-269, 1991.

[23] C. Carbone and J. L. Gittleman, "A common rule for the scaling of carnivore density," Science, vol. 295, no. 5563, pp. 2273-2276, 2002.

[24] W. Jetz, C. Carbone, J. Fulford, and J. H. Brown, "The scaling of animal space use," Science, vol. 306, pp. 266-268, 2004.

[25] J. Damuth, "Interspecific allometry of population density in mammals and other animals: the independence of body mass and population energy-use," Biological Journal of the Linnean Society, vol. 31, no. 3, pp. 193-246, 1987. 
[26] A. F. Bennett and W. R. Dawson, "Metabolism," in Biology of the Reptilia, C. Gans and W. R. Dawson, Eds., pp. 127-223, Academic Press, New York, NY, USA, 1976.

[27] P. M. Bennett and P. H. Harvey, "Active and resting metabolism in birds: allometry, phylogeny and ecology," Journal of Zoology, vol. 213, no. 2, pp. 327-363, 1987.

[28] B. K. McNab, Basal Rate of Metabolism, Body Size, and Food Habits in the Order Carnivora, Chapman \& Hall, London, UK, 1989.

[29] K. A. Nagy, "Field metabolic rate and food requirement scaling in mammals and birds," Ecological Monographs, vol. 57, no. 2, pp. 111-128, 1987.

[30] K. A. Nagy, "Field metabolic rate and body size," Journal of Experimental Biology, vol. 208, no. 9, pp. 1621-1625, 2005.

[31] B. K. McNab, "Complications inherent in scaling the basal rate of metabolism in mammals," Quarterly Review of Biology, vol. 63, no. 1, pp. 25-54, 1988.

[32] C. Carbone, A. Teacher, and J. M. Rowcliffe, "The costs of carnivory," PLoS Biology, vol. 5, no. 2, pp. 363-368, 2007.

[33] J. F. Gillooly, A. P. Allen, and E. L. Charnov, "Dinosaur fossils predict body temperatures," PLoS Biology, vol. 4, no. 8, p. e248, 2006.

[34] K. Schmidt-Nielsen, Scaling: Why is Animal Size so Important? Cambridge University Press, Cambridge, UK, 1984.

[35] S. Nee, A. F. Read, J. J. D. Greenwood, and P. H. Harvey, "The relationship between abundance and body size in British birds," Nature, vol. 351, no. 6324, pp. 312-313, 1991.

[36] J. H. Brown and B. A. Maurer, "Evolution of species assemblages: effects of energetic constraints and species dynamics on the diversification of the north American avifauna," American Naturalist, vol. 130, no. 1, pp. 1-17, 1987.

[37] M. J. Coe, D. H. Cumming, and J. Phillipson, "Biomass and production of large African herbivores in relation to rainfall and primary production," Oecologia, vol. 22, no. 4, pp. 341354, 1976.

[38] R. East, "Species-area curves and populations of large mammals in African savanna reserves," Biological Conservation, vol. 21, no. 2, pp. 111-126, 1981.

[39] K. G. Van Orsdol, "Ranges and food habits of lions in rwenzn national park, Uganda," Symposium of the Zoological Society of London, vol. 49, pp. 329-340, 1982.

[40] R. East, "Rainfall, soil nutrient status and biomass of large African savanna mammals," African Journal of Ecology, vol. 22, no. 4, pp. 245-270, 1984.

[41] I. Newton, I. Wyllie, and R. Mearns, "Spacing of sparrow hawks in relation to food supply," Journal of Animal Ecology, vol. 55, pp. 361-370, 1986.

[42] M. O'Donoghue, S. Boutin, C. J. Krebs, and E. J. Hofer, "Numerical responses of coyotes and lynx to the snowshoe hare cycle," Oikos, vol. 80, no. 1, pp. 150-162, 1997.

[43] B. Jedrzejewski and W. Jedrzejewski, Predation in Vertebrate Communities: The Baialowieza Primeval Forest as a Case Study, Springer, Berlin, Germany, 1998.

[44] C. J. Krebs, S. Boutin, and R. Boonstra, Ecosystem Dynamics of the Boreal Forest: The Kluane Project, Oxford University Press, Oxford, UK, 2001.

[45] A. H. Hurlbert and J. P. Haskell, "The effect of energy and seasonality on avian species richness and community composition," American Naturalist, vol. 161, no. 1, pp. 83-97, 2003.

[46] N. Pettorelli, J. O. Vik, A. Mysterud, J.-M. Gaillard, C. J. Tucker, and N. Chr. Stenseth, "Using the satellite-derived NDVI to assess ecological responses to environmental change," Trends in Ecology \& Evolution, vol. 20, no. 9, pp. 503-510, 2005.
[47] C. Carbone, J. M. Rowcliffe, G. Cowlishaw, and N. J. B. Isaac, "The scaling of abundance in consumers and their resources: implications for the energy equivalence rule," American Naturalist, vol. 170, no. 3, pp. 479-484, 2007.

[48] M. W. Demment and P. J. Van Soest, "A nutritional explanation for body-size patterns of ruminant and nonruminant herbivores," American Naturalist, vol. 125, no. 5, pp. 641-672, 1985.

[49] L. A. Shipley, J. E. Gross, D. E. Spalinger, N. T. Hobbs, and B. A. Wunder, "The scaling of intake rate in mammalian herbivores," American Naturalist, vol. 143, no. 6, pp. 10551082, 1994.

[50] A. W. Illius and I. J. Gordon, "The physiological ecology of mammalian herbivory," in Nutritional Ecology of Herbivores. Proceedings of the 5th International Symposium on the Nutrition of Herbivores, H. J. G. Jung and G. C. Fahey, Eds., American Society of Animal Science, Savoy, Ill, USA, 1999.

[51] N. Pettorelli, J. Bro-Jørgensen, S. M. Durant, T. Blackburn, and C. Carbone, "Energy availability and density estimates in African ungulates," American Naturalist, vol. 173, no. 5, pp. 698-704, 2009.

[52] S. D. Fretwell and H. L. Lucas Jr., "On territorial behavior and other factors influencing habitat distribution in birds," Acta Biotheoretica, vol. 19, no. 1, pp. 16-36, 1969.

[53] S. Creel and N. M. Creel, "Limitation of African wild dogs by competition with larger carnivores," Conservation Biology, vol. 10, no. 2, pp. 526-538, 1996.

[54] M. L. Gorman, M. G. Mills, J. P. Raath, and J. R. Speakman, "High hunting costs make African wild dogs vulnerable to kleptoparasitism by hyaenas," Nature, vol. 391, pp. 479-481, 1998.

[55] K. R. Crooks and M. E. Soulé, "Mesopredator release and avifaunal extinctions in a fragmented system," Nature, vol. 400, no. 6744, pp. 563-566, 1999.

[56] G. W. Roemer, C. J. Donlan, and F. Courchamp, "Golden eagles, feral pigs, and insular carnivores: how exotic species turn native predators into prey," Proceedings of the National Academy of Sciences of the United States of America, vol. 99, no. 2, pp. 791-796, 2002.

[57] T. M. Caro and C. J. Stoner, "The potential for interspecific competition among African carnivores," Biological Conservation, vol. 110, no. 1, pp. 67-75, 2003.

[58] F. G. T. Radloff and J. T. Du Toit, "Large predators and their prey in a southern African savanna: a predator's size determines its prey size range," Journal of Animal Ecology, vol. 73, no. 3, pp. 410-423, 2004.

[59] M. W. Hayward, "Prey preferences of the spotted hyaena (Crocuta crocuta) and degree of dietary overlap with the lion (Panthera leo.)," Journal of Zoology, vol. 270, no. 4, pp. 606-614, 2006.

[60] A. N. Facka, P. L. Ford, and G. W. Roemer, "A novel approach for assessing density and range-wide abundance of prairie dogs," Journal of Mammalogy, vol. 89, no. 2, pp. 356-364, 2008.

[61] R. Hengeveld and J. Haeck, "The distribution of abundance. I. Measurements,” Journal of Biogeography, vol. 9, pp. 303-316, 1982.

[62] J. H. Brown, "On the relationship between abundance and distribution of species," American Naturalist, vol. 124, pp. 255-279, 1984.

[63] K. J. Gaston, "Geographic range limits: achieving synthesis," Proceedings of the Royal Society B, vol. 276, no. 1661, pp. 1395-1406, 2009. 
[64] S. K. Morgan Ernest, B. J. Enquist, J. H. Brown, et al., "Thermodynamic and metabolic effects on the scaling of production and population energy use," Ecology Letters, vol. 6, no. 11, pp. 990-995, 2003.

[65] B. J. Enquist, J. H. Brown, and G. B. West, "Allometric scaling of plant energetics and population density," Nature, vol. 395, no. 6698 , pp. $163-165,1998$.

[66] P. E. Schmid, M. Tokeshi, and J. M. Schmid-Araya, "Relation between population density and body size in stream communities," Science, vol. 289, no. 5484, pp. 1557-1560, 2000.

[67] J. E. Cohen, T. Jonsson, and S. R. Carpenter, "Ecological community description using the food web, species abundance, and body size," Proceedings of the National Academy of Sciences of the United States of America, vol. 100, no. 4, pp. 1781-1786, 2003.

[68] M. Wikelski, "Evolution of body size in Galapagos marine iguanas," Proceedings of the Royal Society B, vol. 272, no. 1576, pp. 1985-1993, 2005.

[69] R. Shine, P. S. Harlow, J. S. Keogh, and Boeadi, "The influence of sex and body size on food habits of a giant tropical snake, Python reticulatus," Functional Ecology, vol. 12, no. 2, pp. 248-258, 1998.

[70] C. Mattison, Snake, DK Publishing, New York, UK, USA, 1999.

[71] P. Cotgreave, "The relation between body size and abundance in a bird community: the effects of phylogeny and competition," Proceedings of the Royal Society of London B, vol. 256, no. 1346, pp. 147-149, 1994.

[72] P. Pafilis, J. Foufopoulos, N. Poulakakis, P. Lymberakis, and E. Valakos, "Digestive performance in five mediterranean lizard species: effects of temperature and insularity," Journal of Comparative Physiology B, vol. 177, no. 1, pp. 49-60, 2007.

[73] J. D. Litzgus and W. A. Hopkins, "Effect of temperature on metabolic rate of the mud turtle (Kinosternon subrubrum)," Journal of Thermal Biology, vol. 28, no. 8, pp. 595-600, 2003.

[74] T. Tregenza, "Building on the ideal free distribution," Advances in Ecological Research, vol. 26, pp. 253-307, 1995. 

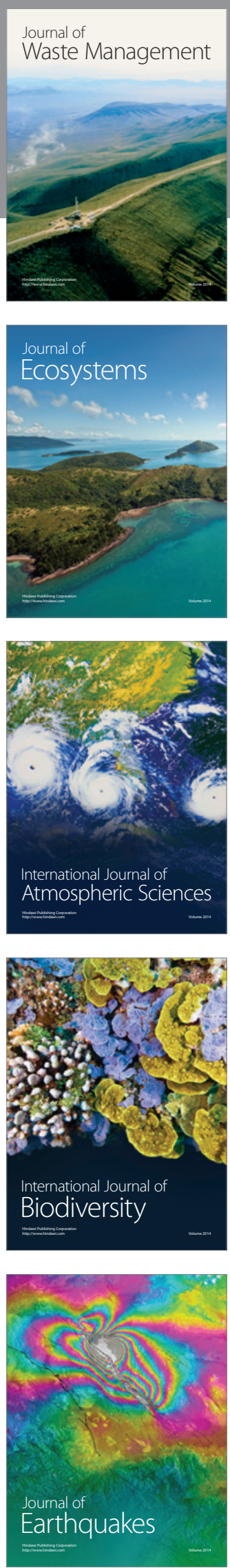
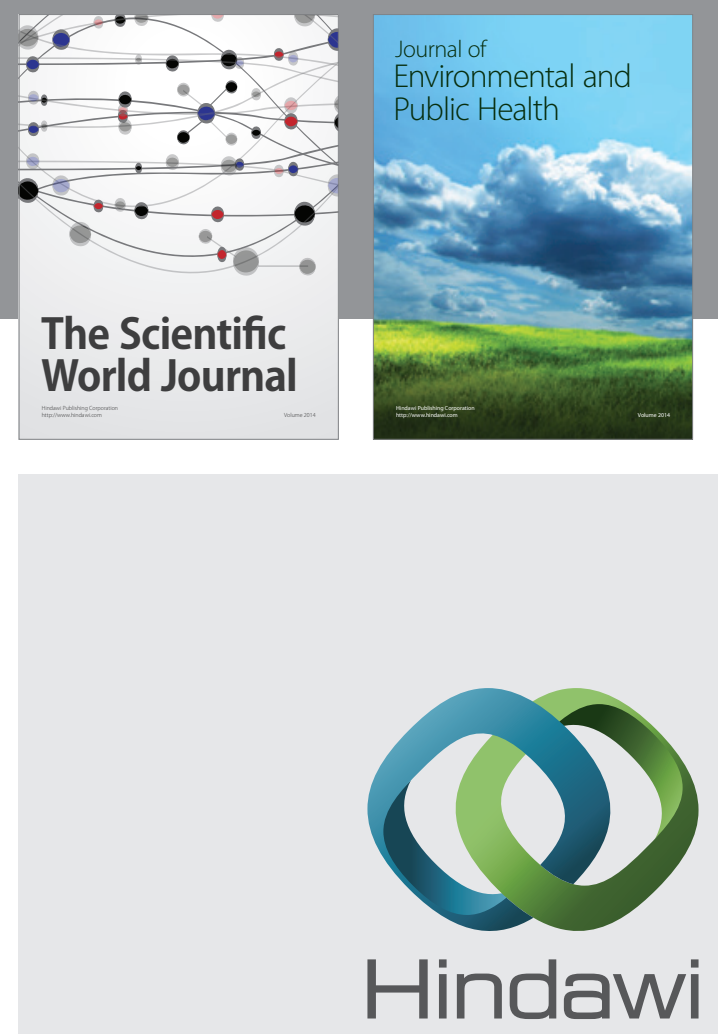

Submit your manuscripts at

http://www.hindawi.com
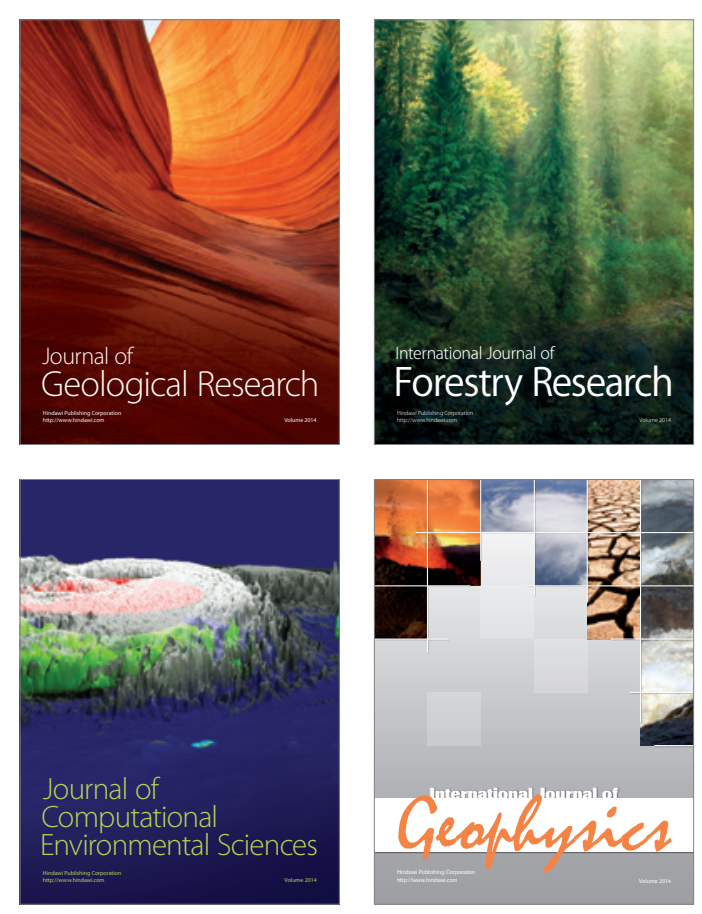
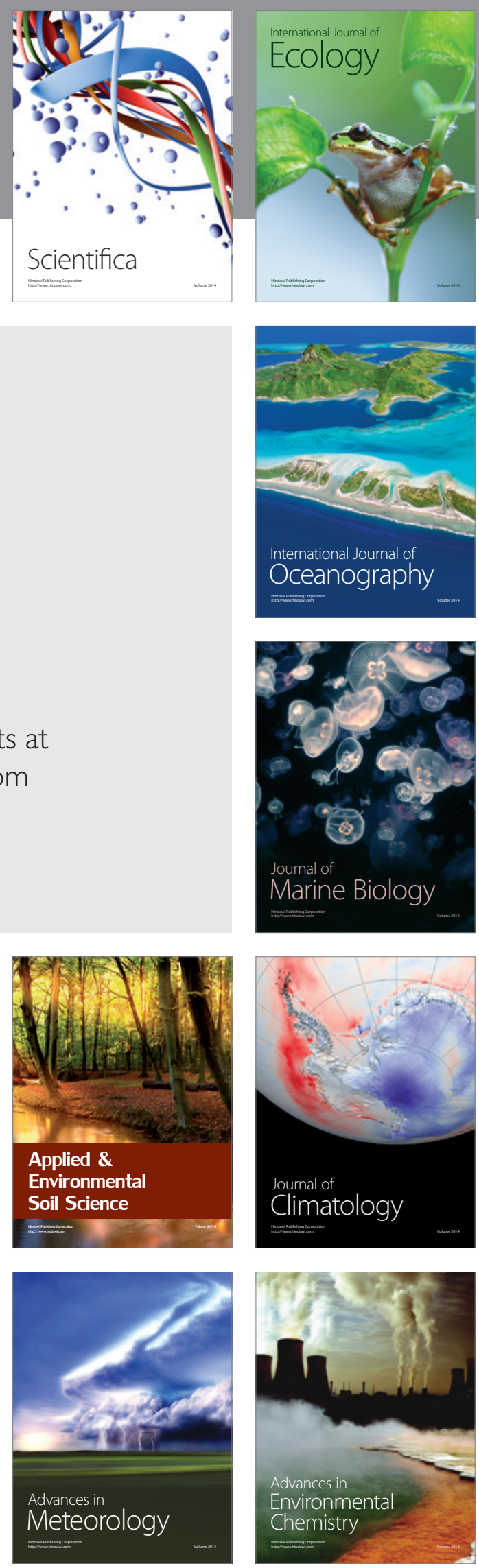